\title{
Surveying the Relationship between Psychological Disorders and Spending Time on Facebook
}

\author{
Nasrin Yeganeh Rad*, Toozandehjani Hassan\# \\ Department of Psychological Sciences, Faculty of Humanities, Neyshabur Branch, Islamic Azad University, Neyshabur, Iran \\ Email: ${ }^{*}$ H.Toozandehjani@ymail.com
}

How to cite this paper: Rad, N.Y. and Hassan, T. (2017) Surveying the Relationship between Psychological Disorders and Spending Time on Facebook. Social Networking, 6, 197-205.

https://doi.org/10.4236/sn.2017.62012

Received: December 12, 2016

Accepted: April 27, 2017

Published: April 30, 2017

Copyright (c) 2017 by authors and Scientific Research Publishing Inc. This work is licensed under the Creative Commons Attribution International License (CC BY 4.0).

http://creativecommons.org/licenses/by/4.0/

\begin{abstract}
Introduction: This research is a descriptive and correlational research which has been done with the purpose of surveying the relationship between mental disorders and the amount of time that people spend on Facebook. 147 members out of Facebook active users were chosen randomly. Then epidemiology questionnaire of mental disorders (SCL-90-R) was used to collect data. Data analysis was done using Spearman correlation coefficient and multiple regression. The results showed that there was a significant relation between characters such as aggression, obsession, psychosis, paranoia, depression and using Facebook $(\mathrm{p}<0.05)$, but this relation was not significant in anxiety, interpersonal sensitivity, physical complaints and phobia. Furthermore, this relationship was significant regarding to subjects' gender and marital status $(\mathrm{p}<0.05)$, but there was no relationship regarding to their age.
\end{abstract}

\section{Keywords}

Mental Disorders, Psychological Disorders, Facebook

\section{Introduction}

Facebook is a virtual social network in which its users are able to share personal information, photos, being members of various groups, and joining people who are in their friends' list [1]. Although various social networks have been established whole over the world in order to make the relationship between people, Facebook has been known as the loveliest social network among students [2]. At the moment, there are 1.23 billion active users out of 1.26 billion Facebook users. 60 percent of users use Facebook daily. Each user has 250 people in his friends' list,

${ }^{\star}$ B.A. in General Psychology.

\#Assistant Professor of Psychology. 
on average, and whole users spend 20 billion minutes in Facebook site daily [3].

Mental disorder is a syndrome or a behavioral or psychological pattern, clinically significant, that individual suffers it, along with disease, disability, the increase of the risk of pain, death, discomfort, disability and losing freedom. Meanwhile, this pattern or syndrome must not be predictable or a cultural response to a special event; and, with each primary cause, it should be considered as a behavioral, psychological or biological malfunction [4].

A lot of researches have been done about spending time on Facebook, mental disorders and the harms and benefits of using this social network. Doherty and Schlenker found out that people with high level of public self-consciousness had more concern about social standards matching. Therefore, these people may put limited information on their Facebook page to avoid destroying their prestige. People with low-level of public self-consciousness, likely, put much information on their page. [5] stated that adolescents and youth using Facebook were more susceptible to mental disorders such as high emotion, paranoia, aggressive behaviors and being antisocial.

[6] found out, in a research, that long lasting the period of adolescence and youth, prevalence of new methods of social behaviors to spend living space, individualization and fading usual social cracks, importance of life style, life policy for the youth, the dissolution of traditional social neighborhood and urban renewal were the major context leading the youth to spend time in the internet and on Facebook.

[7] [8] found out that no considerable change had happened in the way of using Facebook, during the time. But users' and audiences' perception and their orientations have had the considerable change during the time. Moreover, the most important motive of using Facebook has been to keep old-relationships rather than making new relationships. Furthermore, using Facebook has relation with psychological welfare criteria; and this relation was more useful for users with low self-esteem and low life-satisfaction.

[9] by surveying 451 students in various universities of the USA found out that each user has 217 friends in Facebook, on average; and there is a positive correlation between the number of friends and extrovert personality. According to [10], individuals' believes about using web gates such as Facebook, has correlation with self-monitoring personality character. It seems that self-monitoring character is effective on the information individuals put on their Facebook page. [11] concluded that there is a positive correlation between the use of Facebook and extrovert characteristic.

[12] showed that university student, often use Facebook to keep relationships, university purposes and information exchange. [13] found out, by a study on bachelor student, the more self-disclosing professors do, the more trust students have on them. Moreover, Facebook causes self-disclosure and consequently getting trust and forming friendly relationships.

[14] concluded, by a study on bachelor students, that student spend 38 minutes per day on Facebook, on average and they have great tendency to self-disclosing. 
Furthermore, there is a positive correlation between the need of popularity and self-disclosure. [15] surveyed the behavior and habits of user sat the age of 18 to 25, about how they use Facebook, and found out that these people, are, often, self-grandiose and they have low self-esteem.

To this research, there is a direct correlation between page checking times on Facebook during the day and the amount of their narcissism.

[16] found out that there is a relation between personality characters, such as self-monitoring and public self-consciousness, and tendency to using Facebook. Individuals with low self-monitoring and high public self-conscious characters prefer to put little details on their Facebook page and they are more cautious in updating their information; while individuals with high self-monitoring put a lot of information with details on their Facebook page.

[17] showed that there is a relation between using Facebook and the average of students' marks and their study rate. So that the average of students' marks who using Facebook, was lower and they spend little time study, weekly. [18] stated that students using Facebook, likely, experience more depression and loneliness. [19] found out that there is a relation between narcissism and self-esteem and the amount of time spending on Facebook. So that there is a negative relation between self-esteem and the rate of profile updating; and a positive relation between tendency to have many friends on Facebook and narcissism. Gabber and Kumar found out that students studying mathematics, who use Facebook, have higher level of stress and less control on events around them. [19] found out that there is a relation between body image of 33 young girls and their spending time on Facebook. Spending time on Facebook by young girls, actively, has relation with overweighting dissatisfaction, thinness tendency and internalizing thinness pattern.

In these studies, there is a lack of studies reasoning unsuitable spending time on Facebook. It seems mental disorders could have an effective role in the time spending in these social networks. Indeed, this research aims surveying the effect of mental disorders on the amount of time spending on Facebook by individuals.

\section{Methods}

The method of this research is correlation, and it surveys the relation between using Facebook and mental disorders. Statistical population of this research was 147 people ( 80 men and 67 women) who used to use Facebook actively, from April 2013 for three months. Sampling method was multistage random cluster. So that 3 days of a week were selected randomly and then the hours of selecting sample group were selected between 7 to 24 (midnight) randomly and then the sample was selected from online Facebook users, by simple random method.

\subsection{Research Tools}

Interview and questionnaire were used to collect sample group information. Interview was done on the times and days selected randomly, via the internet chat and by phone, and then SCL-90-R questionnaire were given to them. Whole 147 
people answered the questionnaire; 15 people of them were put aside from analysing because of defective questionnaire. SCL-90-R questionnaire is one of the most useful diagnostic psychometric tools that was introduced by Dragotice and his colleagues in 1973; and based on clinical experiences and revised psychometric analyses, its final form was developed in 1976 [15] [16] [17] [18] [19]. The questionnaire consisted of 90 items that assesses mental problems in nine dimensions (physical or somatic complaints, obsessive-compulsive, interpersonal sensitivity, depression, anxiety, hostility and aggression, phobia, paranoid and psychotic thoughts). Responses to each question are in a five-degree scale of discomfort, that include any, some, to some extend, much, and intensive.

\subsection{Data Analysis Method}

To describe data, descriptive statistics indicators (mean, standard deviation, histogram) were used, and to analyse data, inferential statistics indicators (Spearman correlation coefficient and multiple variable regression) were used. Analyses were done by SPSS software (version 19).

\subsection{Research Findings}

In Tables 1-3, descriptive information related to nine dimensions of SCL-90-R questionnaire scores, are provided, differentiated by gender, marital status and age.

Table 4 shows that there is a relation between aggression, obsession, paranoia and depression indicators and spending time on Facebook $(\mathrm{p}<0.05)$, and as the correlation coefficient is negative, this relation is reversed. There is no relation between spending time on Facebook and anxiety, interpersonal sensitivity, somatic complaint and phobia indicators. There is a relation between spending time on Facebook and psychosis indicator $(\mathrm{p}<0.05)$, and as correlation coefficient is positive, it is direct relation. Since there is a probability that the effect of each research variable is because of demographic characteristics (age, gender,

Table 1. Mean, standard deviation of nine dimensions of SCL-90-R questionnaire scores, differentiated by gender.

\begin{tabular}{lccccc}
\hline & & \multicolumn{2}{c}{ Mean } & \multicolumn{2}{c}{ Standard deviation } \\
\cline { 2 - 5 } & & Men & Women & Men & Women \\
\hline 1 & Aggression & 1.42 & 1.40 & 0.63 & 0.60 \\
3 & Anxiety & 1.21 & 1.21 & 0.53 & 0.73 \\
4 & Obsession & 1.35 & 1.45 & 0.42 & 0.55 \\
5 & Interpersonal sensitivity & 1.22 & 1.36 & 0.55 & 0.52 \\
6 & Somatic complaint & 1.00 & 1.33 & 0.51 & 0.64 \\
7 & Psychosis & 0.87 & 0,97 & 0.53 & 0.71 \\
8 & Paranoid thoughts & 1.36 & 1.45 & 0.66 & 0.62 \\
9 & Depression & 1.28 & 1.41 & 0.46 & 0.65 \\
\hline
\end{tabular}


Table 2. Mean, standard deviation of nine dimensions of SCL-90-R questionnaire scores, differentiated by marital status.

\begin{tabular}{lccccc}
\hline & & \multicolumn{2}{c}{ Mean } & \multicolumn{2}{c}{ Standard deviation } \\
\cline { 3 - 6 } & & Single & Married & Single & Married \\
\hline 1 & Aggression & 1.39 & 1.44 & 0.60 & 0.63 \\
2 & Anxiety & 1.14 & 1.32 & 0.68 & 0.55 \\
3 & Obsession & 1.46 & 1.32 & 0.48 & 0.50 \\
4 & Interpersonal sensitivity & 1.31 & 1.27 & 0.48 & 0.50 \\
5 & Somatic complaint & 1.11 & 1.25 & 0.59 & 0.61 \\
6 & Psychosis & 0.86 & 1.01 & 0.59 & 0.67 \\
7 & Paranoid thoughts & 1.39 & 1.43 & 0.64 & 0.63 \\
8 & Depression & 1.28 & 1.45 & 0.53 & 0.61 \\
9 & Phobia & 0.81 & 1.09 & 0.55 & 0.69 \\
\hline
\end{tabular}

Table 3. Mean, standard deviation of nine dimensions of SCL-90-R questionnaire scores, differentiated by age.

\begin{tabular}{lccccccc}
\hline & & & Mean & \multicolumn{5}{c}{ Standard deviation } \\
& & $<20$ & $21-30$ & $>30$ & $<20$ & $21-30$ & $>30$ \\
1 & Aggression & 1.42 & 1.42 & 1.37 & 0.48 & 0.68 & 0.53 \\
2 & Anxiety & 1.34 & 1.15 & 1.25 & 0.58 & 0.67 & 0.56 \\
3 & Obsession & 1.26 & 1.31 & 1.52 & 0.50 & 0.43 & 0.60 \\
4 & Interpersonal sensitivity & 1.39 & 1.35 & 1.31 & 0.46 & 0.56 & 0.62 \\
5 & Somatic complaint & 1.23 & 1.09 & 1.12 & 0.39 & 0.55 & 0.66 \\
7 & Psychosis & 0.94 & 0.78 & 1.06 & 0.60 & 0.52 & 0.73 \\
8 & Paranoid thoughts & 1.13 & 1.56 & 1.21 & 0.55 & 0.62 & 0.65 \\
9 & Depression & 1.23 & 1.35 & 1.51 & 0.41 & 0.59 & 0.63 \\
\hline & Phobia & 1.34 & 0.81 & 0.79 & 0.48 & 0.64 & 0.53 \\
\hline
\end{tabular}

Table 4. Summary results of the Spearman correlation coefficient for the Scores of SCL-90-R questionnaire.

\begin{tabular}{lccc}
\hline & & \multicolumn{2}{c}{ Facebook } \\
\cline { 3 - 4 } & & Correlation coefficient & Significance level \\
\hline 1 & Aggression & -0.345 & -0.000 \\
2 & Anxiety & -0.073 & 0.370 \\
3 & Obsession & -0.378 & 0.000 \\
4 & Interpersonal sensitivity & -0.125 & 0.130 \\
5 & Somatic complaint & 0.034 & 0.682 \\
6 & Psychosis & 0.168 & 0.041 \\
7 & Paranoid thoughts & -0.248 & 0.002 \\
8 & Depression & -0.228 & 0.005 \\
9 & Phobia & 0.120 & 0.147 \\
\hline
\end{tabular}


Table 5. Summary results of the Spearman correlation coefficient for the Scores of SCL-90-R questionnaire, regarding subjects' demographic characteristics.

\begin{tabular}{ccccc}
\hline \multicolumn{2}{c}{ Spearman correlation coefficient } & Age & Marital status & Gender \\
\hline \multirow{2}{*}{ Facebook } & Correlation coefficient & 0.054 & 0.163 & 0.222 \\
& Significance level & 0.515 & 0.049 & 0.007 \\
\hline
\end{tabular}

Table 6. Summary data of regression model.

\begin{tabular}{ccccc}
\hline Model & $\begin{array}{c}\text { Multiple correlation } \\
\text { coefficient }\end{array}$ & $\begin{array}{c}\text { Model determining } \\
\text { coefficient }\end{array}$ & $\begin{array}{c}\text { Indicator determining } \\
\text { coefficient }\end{array}$ & $\begin{array}{c}\text { Standard } \\
\text { error }\end{array}$ \\
\hline 1 & 0.418 & 0.175 & 0.121 & 0.439 \\
\hline
\end{tabular}

Table 7. Summary results of multifactorial analysis of variance.

\begin{tabular}{cccccc}
\hline Regression model & Total squares & degrees of freedom & Arithmetic square & $\mathrm{F}$ & $\mathrm{p}$ \\
\hline 1 & 5.588 & 9 & 0.621 & 3.224 & 0.001 \\
\hline
\end{tabular}

marital status), the correlation among these three issues and spending time on Facebook was studied, as well.

Regarding the information of Table 5, there is direct and significant relation between gender and marital status and spending time on Facebook $(\mathrm{p}<0.05)$; but, there is no significant relation between age and spending time on Facebook $(\mathrm{p}>0.05)$. In this section multiple variable regression is used to determine the effects of nine dimensions of mental disorders on spending time on Facebook. Table 6 and Table 7 show the data associated with regression model.

Multiple correlation coefficient is 0.418 that shows the amount of correlation between spending time on Facebook and nine dimensions on mental disorders of SCL-90-R questionnaire together, indeed. The value of coefficient of determination shows that these nine dimensions, all together, are 17.5 percent of the explanation of spending time on Facebook. As it seems, the value of SE is very small that means rather accurate prediction of regression model.

As it is seen, our hypothesis, the significance of the regression model, is correct $(\mathrm{p}<0.05)$.

In Table 8, each of independent variables has been calculated and its significance has been tested. As it is seen, the relation between aggression, obsession, psychosis, paranoia and depression indicators and spending time on Facebook is significant $(\mathrm{p}<0.05)$. Therefore, it seems these disorders could predict individuals' spending time on Facebook, but this relation in anxiety, interpersonal sensitivity, somatic complaint and phobia is not significant.

\section{Discussion and Conclusion}

The survey of correlation between mental disorders and spending time on Facebook, using the Spearman correlation coefficient, showed that the relation between aggression, obsession, psychosis, paranoia and depression indicators and spending time on Facebook was significant; but in anxiety, interpersonal sensi- 
Table 8. Estimating model coefficient and significance of coefficients.

\begin{tabular}{cccccc}
\hline \multicolumn{5}{c}{ Coefficients } \\
\hline Model & $\begin{array}{c}\text { Non-standard } \\
\text { coefficients }\end{array}$ & $\begin{array}{c}\text { Standard } \\
\text { coefficients }\end{array}$ & t & $\begin{array}{c}\text { Level of } \\
\text { significance }\end{array}$ \\
\hline B & Standard Error & Beta & & \\
Aggression & 1.594 & 0.137 & 0.066 & 11.605 & 0.000 \\
Anxiety & 0.014 & 0.017 & -0.141 & 0.822 & 0.003 \\
Obsession & -0.107 & 0.063 & 0.059 & -1.706 & 0.365 \\
Interpersonal sensitivity & -0.005 & 0.007 & -0.75 & 0.733 & 0.000 \\
Somatic complaint & -0.001 & 0.007 & -0.008 & -0.924 & 0.141 \\
Psychosis & 0.200 & 0.062 & -0.189 & 3.237 & 0.032 \\
Paranoid thoughts & -0.133 & 0.062 & -0.161 & -2.147 & 0.004 \\
Depression & -0.129 & 0.070 & 0.079 & 1.842 & 0.005 \\
Phobia & 0.058 & 0.060 & 0.06 & 0.971 & 0.214 \\
\hline
\end{tabular}

tivity, somatic complaint and phobia indicators, it was not significant. Therefore, it seems these disorders could cause greater use of the networks in which individual can experience interaction in a way different from what is in real world. These results are consistent with the results of the most researches mentioned before [7] [8] [9] [10] [13] [15].

In the survey on the value of correlation between demographic characteristics and spending time on Facebook, it was found out that there was the positive correlation between gender and spending time on Facebook. These results are consistent with the results of the researches done by [4] stated that women's tendency to be applied for membership of Facebook is more than men's tendency. Furthermore, there is the significant correlation between marital status and spending time on Facebook. Regarding positive coefficient of correlation, it is direct correlation, but there is negative correlation between age and spending time on Facebook.

In addition, the result of regression analysis showed that some mental disorders such as aggression, obsession, psychosis, paranoia and depression could predict spending time on Facebook. These results are consistent with researches done by [18]. They stated that extroversion and neuroticism predicted using Facebook. These results support the results of the researches done by Doherty and Schlenker (1991) and Gagulnski (2010) that said public self-consciousness and self-monitoring indicators predict the way in which people use Facebook.

Finally, it can be concluded that certain personality traits can lower a person's relationship with what exists in reality and take him to the virtual and fantasy world by using networks such as Facebook and chat rooms. Therefore, it is suggested to other researchers to take virtual relationship networks to the realm of psychology and discuss disorders causes using these networks more, and the effects of these networks on individuals. 


\section{References}

[1] Facebook (2014) Newsroom. Facebook.

[2] www.facebook.com/press/info.php?statistics.Technique

[3] Golder, S.A., Wilkinson, D. and Huberman, B.A. (2007) Rhythms of Social Interaction: Messaging within a Massive Online Network. In: Steinfield, C., Pentland, B.T., Ackerman, M. and Contractor, N., Eds., Communities and Technologies 2007, Springer, London. https://doi.org/10.1007/978-1-84628-905-7_3

[4] Kaplan, H. and Sadock, J. (1995) Comprehensive Text Book of Psychiatry. 6th Edition, Lo Williams and Wilkins, Philadelphia.

[5] Kirschner, P.A. and Karpinski, A.C. (2010) Facebook and Academic Performance. Computers in Human Behavior, 26, 1237-1245. https://doi.org/10.1016/j.chb.2010.03.024

[6] Kolek, E.A. and Saunders, D. (2008) Online Disclosure: An Empirical Examination of Undergraduate Face Book Profiles. NASPA Journal, 45, 1-25.

https://doi.org/10.2202/0027-6014.1905

[7] Lampe, C., Ellison, N. and Steinfield, C. (2007) A Familiar Face(book): Profile Elements as Signals in an Online Social Network. Proceedings of the 26th Annual SIG CHI Conference on Human Factors in Computing Systems, ACM, New York, 435444. https://doi.org/10.1145/1240624.1240695

[8] Boning, E.R. (1993) Un Dimensionality of SCL-90-R Scale in Adult and Adolescent Crisis Samples. Journal of Clinical Psychology, 49, 212-215. https://doi.org/10.1002/1097-4679(199303)49:2<212::AID-JCLP2270490213>3.0.CO ;2-V

[9] Ellison, N., Steinfield, C. and Lampe, C. (2007) The Benefits of Face Book "Friends": Social Capital and College Students' Use of Online Social Network Sites. Journal of Computer-Mediated Communication, 12, 1143-1168. https://doi.org/10.1111/j.1083-6101.2007.00367.x

[10] Carpenter, K.M. and Hittner, J.B. (1995) Dimensional Characteristics of the SCL90-R. Journal of Clinical Psychology, 51, 383-390.

https://doi.org/10.1002/1097-4679(199505)51:3<383::AID-JCLP2270510310>3.0.CO $\underline{; 2-\mathrm{Q}}$

[11] Christofides, E., Muise, A. and Desmarais, S. (2009) Information Disclosure \& Control on Facebook: Are They Two Sides of the Same Coin or Two Different Processes? Cyber Psychology \& Behavior, 12, 341-345. https://doi.org/10.1089/cpb.2008.0226

[12] Doherty, K. and Schlenker, B. (1991) Self-Consciousness and Strategic Selfpresentation. Journal of Personality, 59, 1-18. https://doi.org/10.1111/j.1467-6494.1991.tb00765.x

[13] Lampe, C., Ellison, N. and Steinfield, C. (2008) Changes in Use and Perception of Face Book. Proceedings of the ACM2008 Conference on Computer Supported Cooperative Work, ACM, New York, 721-730.

[14] Lin, C.S. (2008) Exploring the Personality Trait of Self-Monitoring on Technology Usage of Web Portals. Cyber Psychology \& Behavior, 11, 235-238.

https://doi.org/10.1089/cpb.2007.0021

[15] Maser, J.P., Murphy, R.E. and Symonds, C.J. (2009) The Effects of Teacher Self Disclosure via Face Book on Teacher Credibility. Learning, Media and Technology, 34, 175-183. https://doi.org/10.1080/17439880902923655

[16] Meier, E.P. and Gray, J. (2014) Face Book Photo Activity Associated with Body Image Disturbance in Adolescent Girls. Cyberpsychology, Behavior, and Social Networking, 17, 199-206. https://doi.org/10.1089/cyber.2013.0305 
[17] A Social Influence Model of Consumer Participation in Network and SmallGroup-Based Virtual Communities. International Journal of Research in Marketing, 21, 241-226. https://doi.org/10.1016/j.ijresmar.2003.12.004

[18] Ross, C., Orr, E.S., Sisic, M., Arseneault, J.M., Simmering, M.G. and Orr, R.R. (2009) Personality and Motivations Associated with Face Book Use. Computers in Human Behavior, 25, 578-586. https://doi.org/10.1016/j.chb.2008.12.024

[19] Gogolinski, T.B. (2010) Effects of Self-Monitoring and Public Self-Consciousness on Perceptions of Face Book Profiles. Colonial Academic Alliance Undergraduate Research Journal, 1, Article 9.

Submit or recommend next manuscript to SCIRP and we will provide best service for you:

Accepting pre-submission inquiries through Email, Facebook, LinkedIn, Twitter, etc. A wide selection of journals (inclusive of 9 subjects, more than 200 journals)

Providing 24-hour high-quality service

User-friendly online submission system

Fair and swift peer-review system

Efficient typesetting and proofreading procedure

Display of the result of downloads and visits, as well as the number of cited articles Maximum dissemination of your research work

Submit your manuscript at: http://papersubmission.scirp.org/

Or contact sn@scirp.org 